\title{
DEVELOPMENT AND OPTIMIZATION OF RIZATRIPTAN BENZOATE ETHOSOMES
}

\author{
MILIND P. WAGHa, SWATI S. MUTHA BORA ${ }^{\mathrm{a}, \mathrm{b}^{*}}$ \\ aDepartment of Pharmaceutics, MVP Samaj's College of Pharmacy, Nashik, India, bDepartment of Pharmaceutics, S. G. R. S. College of \\ Pharmacy, Saswad, Pune, India \\ Email: swati.mutha@rediffmail.com \\ Received: 19 Dec 2017, Revised and Accepted: 13 Feb 2018
}

\begin{abstract}
Objective: The objective of this study was to assess the development of ethosomal drug delivery system for site-specific topical delivery of rizatriptan benzoate (RBZ) for sustained action.

Methods: In the present study ethosomes were prepared using the cold method. The formulation was optimized using $3^{3}$ full factorial designs. The lipid concentration $\left(\mathrm{X}_{1}\right)$, ethanol concentration $\left(\mathrm{X}_{2}\right)$ and stirring speed $\left(\mathrm{X}_{3}\right)$ were selected as independent factors and the vesicle size $\left(\mathrm{Y}_{1}\right)$ and \% entrapment efficiency $\left(\mathrm{Y}_{2}\right)$ were selected as dependent variables.

Results: The equation of multiple regression revealed that there was no significant interaction among factors. The lipid concentration had a positive effect on vesicle size while ethanol concentration and stirring speed had a negative effect. For entrapment efficiency, all factors showed a positive effect while lipid concentrative found to be the main influencing factor. The formulation F4E459 (4\% SPC, 45\% v/v ethanol 900 RPM), which was characterized by optimum vesicle size $(5.5 \mu \mathrm{m})$ and high entrapment efficiency (93.32\%), was considered to be an optimal formulation. The scanning electron microscopy (SEM) results showed that RBZ ethosome have a smooth surface. The polydispersity index (PI) and zeta potential of the optimized formulation were found to be $0.493 \pm 0.021$ and-21.3 $\mathrm{mV}$ respectively. In vitro permeation through rat abdominal skin from the ethosomal gel followed Higuchi diffusion model over a period of $8 \mathrm{~h}$.
\end{abstract}

Conclusion: The results obtained in this research work clearly indicated a promising potential of ethosomal carrier system of RBZ for migraine treatment with a topical approach for sustained action.

Keywords: Ethosomes, Triptan, Topical targeted drug delivery, Permeation, Gel

(C) 2018 The Authors. Published by Innovare Academic Sciences Pvt Ltd. This is an open access article under the CC BY license (http://creativecommons.org/licenses/by/4.0/) DOI: http://dx.doi.org/10.22159/ijap.2018v10i2.24354

\section{INTRODUCTION}

RBZ is a potent and selective serotonin (5-HT1B/1D) receptor agonist. It is a second-generation Triptan and used in the acute treatment of migraine attacks with or without aura and cluster headaches [1-3]. RBZ is available in the market as tablet and wafer form [4]. A migraine many times associated with nausea, vomiting and gastric stasis which make oral route unsuitable. It is also reported that the oral bioavailability of RZB is only $45 \%$ due to hepatic first pass effect and half-life is $2-3 \mathrm{~h}$, so require frequent administration [5]. As an episodic condition of a migraine, later on, may become chronic, therefore need to develop a sustained release dosage form as alternate route of administration.

Recently it was investigated that topical administration of triptans may include increased efficiency by avoiding the first-pass effect of the liver, avoiding discomfort and risks of an intravenous treatment, avoiding side effects in the region of the gastrointestinal tract in the case of oral medication, and good patient acceptance. Absorption peaks involving the risk of systemic side effects may also be avoided [6]. In the literature, topical/transdermal delivery of RZB has been suggested to be beneficial by different authors [5, 7-9]. Recently As per European patent No 1435945 a concept of topical regional neuroaffetive (TRNA) therapy in which action of triptan at peripheral neural synapse take place after topical application at posterior cervical region i. e back of the ear, preferably in close proximity to or on the area of skin above the brain stem had been proposed [6]. In TRNA therapy drug need only transverse the stratum corneum of the skin to reach cutaneous free nerve endings for therapeutic effect. This alternate route of administration will promote drug localization at peripheral neural synapse containing 5-HT1D/1F receptors, activation of these receptors will inhibit the neurotransmitter release like CGRP and will also be avoided cardiac side effects associated with RBZ [10]. The main obstacle of crossing stratum corneum (SC) can be overcome by using flexible vesicular drug delivery system like ethosome [11-13]. These vesicular systems have the capacity to load both lipophilic as well as the hydrophilic drug. Unlike other vesicular systems, ethosomes can better encapsulate hydrophilic moieties [14]. The aim of this study was to assess the applicability of ethosome drug delivery system for sustained and site specific delivery of RBZ through the topical application to cranial skin.

\section{MATERIALS AND METHODS}

\section{Materials}

Rizatriptan benzoate was obtained as a gift sample from Cipla Ltd, Kurkumbh, soyaphosphatidyl choline (SPC) (Sigma Chemicals) were used. Demineralize and double distilled water were used Carbopol® 934 (SD Fines Chemical Ltd, Mumbai), ethanol absolute, propylene glycol (Merck, Mumbai). All other chemicals were of HPLC grade and used without further modification.

\section{Analytical method}

RBZ was analysed for percent entrapment efficiency (\%EE), percent cumulative drug release (\% CDR) and percent diffusion study by UV double beam spectrophotometer (Shimadzu-1800, Japan) in phosphate buffer $\mathrm{pH} 6.8$ by generating a standard curve for the range from 0 to $5 \mu \mathrm{g} / \mathrm{ml}$ at $225 \mathrm{~nm}$ [15].

\section{Preparation of ethosomes}

Ethosomes were prepared by the cold method, as reported and described earlier [12, 16, 17]. Briefly, in a completely dried glass vial, SPC was dissolved in ethanol by vigorous stirring. Propylene glycol is added in ethanol solution. The glass vial was sealed up completely and connected with a tube to a syringe system to allow the addition of water and to avoid ethanol evaporation as far as possible. This mixture was heated to $30{ }^{\circ} \mathrm{C}$ in a water bath. RBZ was dissolved in phosphate buffer $\mathrm{pH}$ 6.8. The aqueous mixture was heated to $30{ }^{\circ} \mathrm{C}$ in a separate vessel. Then it was added to the ethanolic mixture dropwise in the centre of the vessel. Mixing was continued for an additional $15 \mathrm{~min}$ at $700 \mathrm{rpm}$ in a covered vessel. Ethosomes were formed spontaneously by this process. 


\section{Experimental design}

A $3^{3}$ full factorial design was utilized in the present study. Several studies revealed that the optimized lipid concentration, ethanol concentration and stirring speed plays a notable role in lamellar configuration, on entrapment of the drug and stability of the dispersion system $[11,18-20]$. Here an attempt was made to study the interactive effect of all these variables on ethosome formulation characteristics. The design layout and coded value of independent factor are shown in table 1. The lipid concentration, ethanol concentration and stirring speed were selected as independent variables. The vesicle size, $\% \mathrm{EE}$ and visual stability of dispersion for one week were selected as dependent variables. Minitab 17 trial version was used for the generation and evaluation of the statistical experimental design. An ANOVA test was performed to evaluate the level of significance of the tested factors on the selected responses as well as the interactions between these factors. Application of regression analysis is important to check that our independent variables have a significant effect on our response or not. Surface response plots were also presented to graphically represent the effect of the independent variables on the vesicle size and percentage entrapment efficiency.

Table 1: Composition of different coded values in $3^{3}$ full (general) factorial design of RBZ ethosomes

\begin{tabular}{lllll}
\hline & \multicolumn{3}{l}{ Independent variables (actual values) } & \\
\hline & Coded Values & $\mathbf{X}_{\mathbf{1}}$ : A [SPC concentration (\%)] & $\mathbf{X}_{\mathbf{2}}$ : B [ethanol concentration (\%)] & $\mathbf{X}_{\mathbf{3}}$ : C [stirring speed (Rpm)] \\
\hline Levels & Low (1) & 2 & 35 & 700 \\
& Medium (2) & 3 & 40 & 800 \\
& High (3) & 4 & 45 & 900 \\
\hline
\end{tabular}

\section{Microscopy}

All batches of the ethosomes prepared were viewed under a digital microscope with camera attachment having software to study their size, shape and aggregation property. The ethosomal dispersion was suitably diluted and put on a glass slide and viewed with a binocular microscope with a magnification of $10 \mathrm{X}$.

\section{$\% \mathrm{EE}$}

Ethosomal suspensions were ultra-centrifuged at 14,000 rpm and 4 ${ }^{\circ} \mathrm{C}$ for $90 \mathrm{~min}$. After centrifugation, $1 \mathrm{ml}$ of supernatant was diluted with the addition of $9 \mathrm{ml}$ phosphate buffer $(\mathrm{pH} \mathrm{6.8)}$ and then the absorbance was measured using UV-Vis spectrophotometer by measuring absorbance at $225 \mathrm{~nm}$. The drug entrapment efficiency was calculated as below,

$$
\% \mathrm{EE}=\frac{\mathrm{WT}-\mathrm{WF}}{\mathrm{WT}} \times 100 \%
$$

where $\% \mathrm{EE}$ is the percent entrapment efficiency of the drug, WT is the total amount of RBZ in ethosomal suspension, WF is the free amount of RBZ that was in the supernatants [21].

\section{Visual stability}

Ethosome dispersion stability was observed visually after storing it at $4{ }^{\circ} \mathrm{C}$ for a week. Presence of layer formation, aggregates is indicated stability issue.

\section{Statistical analysis}

Different polynomial equations for different models were generated by using the multiple regression analysis in $3^{3}$ factorial design with the interacting term and regression coefficient for evaluating the responses. The responses were analysed using the quadratic equation. Statistical analysis was carried out using Minitab 17 trial version. The difference is considered statistically significant using ANOVA when $\mathrm{p}<0.05$.

\section{Characterization and evaluation of optimized formulation}

\section{SEM}

Morphology of ethosomes was studied using SEM of the optimized ethosomal formulation was performed for determining the surface morphology, size and shape of the formulation and observing the aggregation property of ethosomes. Selected ethosomal formulation was examined by SEM at different magnification powers at $10 \mathrm{KV}$.

\section{Vesicle size distribution and surface charge}

The vesicle size and size distribution of ethosomes were determined by Malvern Zetasizer based on laser light scattering principle. Light scattering was monitored at $90{ }^{\circ}$ angle and at $25^{\circ} \mathrm{C}$. The mean vesicle size was calculated from the intensity, volume and bimodal distribution assuming spherical particles. The zeta potential is an indication of the stability of the colloidal systems and indicates charge present in colloidal systems. Zeta potential of optimized formulations was determined using Malvern Zetasizer. Samples were placed in clear disposable zeta cells and results were recorded.

\section{Stability evaluation}

The RBZ-loaded F4E459 dispersions were stored in a sealed glass vial and subjected to physical stability study in triplicate. The vials were kept at two different storage conditions, i.e., $4 \pm 2{ }^{\circ} \mathrm{C}$ with ambient humidity and room temperature $25 \pm 2{ }^{\circ} \mathrm{C}$, and the samples were withdrawn periodically at an interval of one month for 3months, suitably diluted with water and analysed for percent encapsulation efficiency. Samples were also observed for uniformity of dispersion.

\section{Preparation of gels}

Gel base was prepared by dispersing 1\% w/v Carbopol 934 in distilled water. The polymer was soaked in water for $2 \mathrm{~h}$ and then dispersed in distilled water using a magnetic stirrer so as to obtain a homogeneous gel adjusting the $\mathrm{pH}$ by using triethanolamine solution [22]. For reparation of ethosomal gel, the ethosomal suspension(s) was centrifuged at $14000 \mathrm{rpm}$ for $20 \mathrm{~min}$, and the pellets obtained were incorporated into the prepared gel base to get $5 \mathrm{mg}$ RBZ per gram.

\section{In vitro skin permeation studies}

Albino rats of Wistar strain of either sex between 200-210 g breed were selected and maintained as per CPCSEA guidelines for the studies. They were fed with standard rodent pelleted chaw and water. Light and dark cycle with $12 \mathrm{~h}$ light and $12 \mathrm{~h}$ dark was maintained. The temperature and relative humidity conditions were $25^{\circ} \mathrm{C} \pm 2{ }^{\circ} \mathrm{C}$ and $60 \pm 10 \%$ respectively. The experiments were performed as per the protocol approved by CSPCSE (CPCSEA; Letter No. SGRS/IAEC/8/2014-15). The animals were fastening overnight but allow water at libitum Hairs from the abdominal side of albino rats was removed by shaving after anaesthetized with ketamine injection. The animals were sacrificed. Abdomen skin was carefully excised. After removing the hypodermal adipose tissue the skin was used as a barrier membrane for the studies. The in vitro skin permeation of RBZ from optimized ethosomal solution and gel prepared with optimized formulation, in comparison with plain drug solution were studied using Franz glass diffusion cell maintained at $32 \pm 1{ }^{\circ} \mathrm{C}$ under nonocclusive conditions using albino abdomen rat skin. The effective permeation area of the diffusion cell was $2.303 \mathrm{~cm}^{2}$. The receptor compartment contained $48.00 \mathrm{ml}$ phosphate buffered $(\mathrm{pH}, 6.8)$ and was constantly stirred at100 rpm. Excised albino abdomen rat skin was mounted between the donor and the receptor compartment. Ethosomal formulation $(1.0 \mathrm{ml})$ was applied to the epidermal surface of the skin. The samples $(1 \mathrm{ml})$ were withdrawn through the sampling port of the diffusion cell at 1-, 2-, 4-, 6-, and 8-h time intervals and analysed. An equal volume of fresh phosphate buffer maintained at $32 \pm 1{ }^{\circ} \mathrm{C}$ was replaced into the receptor compartment after each sampling. The samples were filtered through $0.45 \mu \mathrm{m}$ nylon filter membrane and analysed using spectrophotometer for drug content at 
$225 \mathrm{~nm}$. The cumulative amount of drug permeated per unit area was plotted as a function of time.

\section{Release kinetic studies-release pattern and mechanism}

Data of in vitro RBZ release from ethosomal solution and gel were evaluated kinetically using various mathematical models like zeroorder, first-order, Higuchi and Koresmeyer-Peppas model equations to describe release patterns and mechanisms. Model-dependent methods all rely upon a curve fitting procedure.

\section{Skin irritancy studies}

The skin irritancy (erythema) potential of the ethosomal gel was evaluated. Guidelines of the institutional animal ethics committee were followed for this experiment. Hair on the dorsal side of Wistar albino rats was removed by clipping $1 \mathrm{~d}$ before the experiment. The rats were alienated into 3 groups $(n=3)$. Group I served as the control (saline solution), group II received optimized ethosomal gel and group III received a $0.8 \% \mathrm{v} / \mathrm{v}$ aqueous solution of formalin as a standard irritant. The $0.5 \mathrm{~g}$ of each test product was placed on each area $(25 \times 25 \mathrm{~mm})$, reactions on the skin were measured for $24 \mathrm{~h}$ and $72 \mathrm{~h}$ in the form of erythema. The mean erythemal scores were recorded (ranging from 0 to 4 ) according to Draize scale as no erythema- 0 , very slight erythema (barely perceptible-light pink)-1, well-defined erythema (dark pink)-2,moderate to severe erythema (light red)-3, severe erythema (dark red)-4 [23].

\section{Transmission electron microscopy (TEM)}

Selected ethosomal gel was examined by transmission electron microscopy at different magnification power at $80 \mathrm{KV}$ using transmission electron microscope model JEM@100S (Joel@Japan).

\section{RESULTS AND DISCUSSION}

\section{Ethosome formation}

Ethosomes were spontaneously produced by dissolution of SPC in ethanol along with propylene glycol followed by slow addition of an aqueous buffer under continuous stirring at $30{ }^{\circ} \mathrm{C}$ (fig. 1). During preparation, dispersions displayed initial optical transparency due to the high ethanol concentration which may maintain SPC in solution. By adding increasing concentrations of phosphate buffer, dispersions became turbid. The turbidity of the system is ascribed to a reorganization of SPC molecules within the system, resulting in ethosomal vesicles formation. Propylene glycol used in formulation widely used as a penetration enhancer in a topical formulation, either alone or in combination with other fatty acids. It will enhance solubility and partitioning of the drug in SC, and increase the flux and permeation across SC.

\section{Analysis of factorial design}

Preliminary formulation screening data was utilized for defining design space in $3^{3}$ full factorial designs shown in table 1 for an optimization study. Average vesicular size and percent entrapment efficiency were selected as response parameters, as they play a decisive role in providing topical efficacy of the formulation. Visually evaluated formulation stability as constraining factor was used for selection of optimized stable formulation. Varying phospholipid (2 $\%, 3 \%$ and $4 \% \mathrm{w} / \mathrm{v}$ ), ethanol concentration (35\%,40\% and 45 $\% \mathrm{v} / \mathrm{v})$ and stirring speed $(700,800$ and $900 \mathrm{RPM})$ led to a change in mean vesicular size ranging from 3.5 to $9.0 \mu \mathrm{m}$ (under $10 \mathrm{X}$ magnification) and \% EE from $68.12 \%$ to $93.32 \%$ (table 2).

The ANOVA study (table 3) of the model relating vesicle size as a response is found that no interaction factors are significant $(\mathrm{P} \geq$ 0.05). A multiple regression model fitting for vesicular size response was carried out to obtain a first-order polynomial equation by excluding the terms for which the level of significance was greater than 0.05 , as expressed in equation 1 :

Vesicle Size $=9.000+0.611$ A-1.333 B-0.667 C

This equation revealed that lipid concentration has a positive effect while ethanol concentration and stirring speed both have a negative effect on vesicle size. Ethanol concentration was found to be the dominant factor as per Eqn 1. Ethanol significantly reduces vesicle membrane thickness, probably as a result of the interpenetration of the hydrocarbon chain in the vesicular lipid bilayers [24]. Furthermore, ethanol imparts a net negative charge to the ethosomal system and confers it some degree of steric stabilization that may finally lead to a reduction in vesicular size $[12,25]$. The influences of factors on response Y1 here vesicle size are further supported by a surface plot study as showed in fig. 2 a, b and c.

Table 2: Full factorial design matrix of RBZ ethosomes with evaluation parameters

\begin{tabular}{|c|c|c|c|c|c|c|}
\hline Formulation code & $X_{1}: A$ & $\mathbf{X}_{2}: \mathbf{B}$ & $\mathbf{X}_{3}: \mathbf{C}$ & $Y_{1:}(V S)(\mu \mathrm{m})$ & $Y_{2:}(\% E E)$ & Stability by visual means \\
\hline F2E459 & 2 & 45 & 900 & 3.52 & 78.36 & Stable \\
\hline F2E409 & 2 & 40 & 900 & 5.06 & 74.74 & Stable \\
\hline F2E359 & 2 & 35 & 900 & 6.13 & 71.62 & Stable \\
\hline F2E458 & 2 & 45 & 800 & 4.25 & 76.41 & Stable \\
\hline F2E408 & 2 & 40 & 800 & 5.54 & 72.84 & Stable \\
\hline F2E358 & 2 & 35 & 800 & 7.24 & 70.54 & Stable \\
\hline F2E457 & 2 & 45 & 700 & 5.21 & 73.43 & Stable \\
\hline F2E407 & 2 & 40 & 700 & 6.58 & 69.91 & Stable \\
\hline F2E357 & 2 & 35 & 700 & 7.56 & 68.12 & Stable \\
\hline F3E459 & 3 & 45 & 900 & 4.51 & 84.69 & Stable \\
\hline F3E409 & 3 & 40 & 900 & 6.04 & 78.92 & Stable \\
\hline F3E359 & 3 & 35 & 900 & 7.22 & 76.53 & Stable \\
\hline F3E458 & 3 & 45 & 800 & 5.42 & 79.21 & Stable \\
\hline F3E408 & 3 & 40 & 800 & 7.36 & 75.03 & Stable \\
\hline F3E358 & 3 & 35 & 800 & 8.15 & 72.68 & Stable \\
\hline F3E457 & 3 & 45 & 700 & 6.01 & 75.81 & Stable \\
\hline F3E407 & 3 & 40 & 700 & 7.51 & 72.45 & Stable \\
\hline F3E357 & 3 & 35 & 700 & 8.54 & 70.25 & Not stable \\
\hline F4E459 & 4 & 45 & 900 & 5.48 & 93.32 & Stable \\
\hline F4E409 & 4 & 40 & 900 & 7.26 & 91.80 & Stable \\
\hline F4E359 & 4 & 35 & 900 & 8.12 & 84.61 & Not stable \\
\hline F4E458 & 4 & 45 & 800 & 6.34 & 92.12 & Stable \\
\hline F4E408 & 4 & 40 & 800 & 7.47 & 90.51 & Not stable \\
\hline F4E358 & 4 & 35 & 800 & 8.53 & 81.36 & Not stable \\
\hline F4E 457 & 4 & 45 & 700 & 7.51 & 91.23 & Stable \\
\hline F4E407 & 4 & 40 & 700 & 8.09 & 89.75 & Not stable \\
\hline F4E357 & 4 & 35 & 700 & 8.45 & 76.32 & Not stable \\
\hline
\end{tabular}

Formulation code denotes from left to right as F-formulation, 1 ${ }^{\text {st }}$ digit-SPC concentration(\%), E-ethanol, next two digit ethanol concentration (\%), last digit denotes speed of stirring in hundreds, $\mathrm{X}$ indicates independent variable and $\mathrm{Y}$ indicates dependent variable, A: SPC concentration (\%), B: Ethanol concentration (\%), C: stirring speed (Rpm), $\mathrm{Y}_{1:}$ vesicle average size, $\mathrm{Y}_{2:}$ Percent entrapment efficiency. 


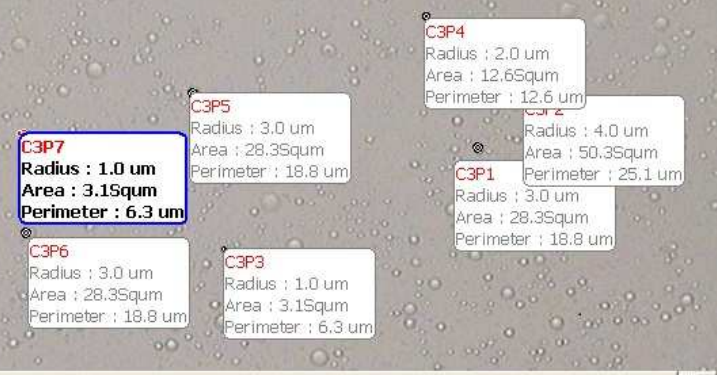

Fig. 1: Microscopic image of ethosomes with 10X magnification

Table 3: Results of ANOVA for the response parameter-vesicle size

\begin{tabular}{|c|c|c|c|c|c|}
\hline Source & Sum of square & DF & Mean square & F-Value & P-Value \\
\hline Model & 54.5972 & 6 & 9.09954 & 115.96 & 0.000 \\
\hline $\mathrm{A}$ & 0.51709 & 1 & 0.51709 & 6.59 & 0.018 \\
\hline $\mathrm{B}$ & 2.4615 & 1 & 2.46154 & 31.37 & 0.000 \\
\hline $\mathrm{C}$ & 0.6154 & 1 & 0.61538 & 7.84 & 0.011 \\
\hline$A^{*} B$ & 0.1875 & 1 & 0.18750 & 2.39 & 0.138 \\
\hline $\mathrm{A}^{*} \mathrm{C}$ & 0.0208 & 1 & 0.02083 & 0.27 & 0.612 \\
\hline $\mathrm{B}^{*} \mathrm{C}$ & 0.0833 & 1 & 0.08333 & 1.06 & 0.315 \\
\hline
\end{tabular}

$\mathrm{A}, \mathrm{B}$ and $\mathrm{C}=$ main factors; $\mathrm{A}^{*} \mathrm{~B}, \mathrm{~A}^{*} \mathrm{C}$, and $\mathrm{B}^{*} \mathrm{C}=$ interactions between main factors; $\mathrm{DF}=$ degree of freedom

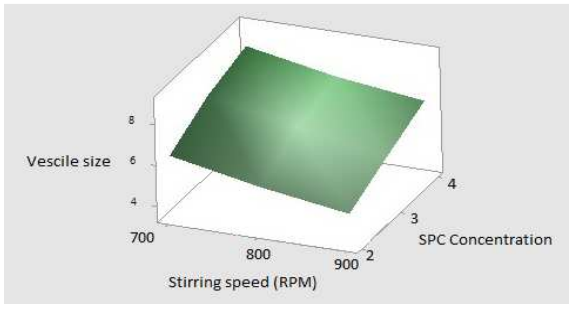

a

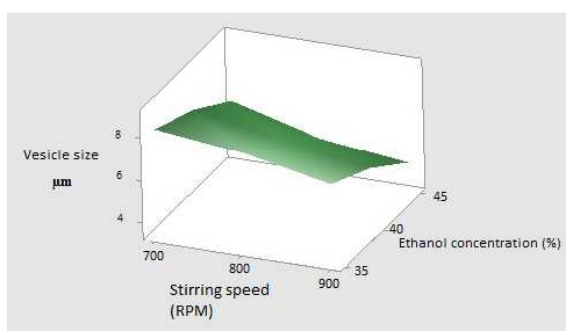

b

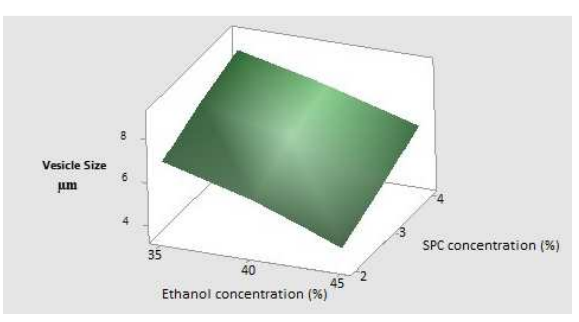

c

Fig. 2: Surface plot of vesicle size, a. Vesicle size VS stirring speed (RPM), SPC concentration (\%), b. Vesicle size VS stirring speed (RPM), ethanol concentration (\%), c. Vesicle size VS ethanol concentration $(\%), S P C$ concentration $(\%)$

The F-value of 31.92 observed with ANOVA data of the model for percent entrapment efficiency as a response (table 4), indicated that the model is significant and all the independent variables, as well as
$\mathrm{AB}$ interaction factor, are found to have a significant effect on the response $(\mathrm{P} \leq 0.005)$.

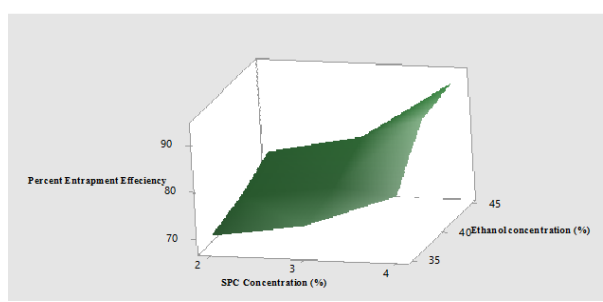

a

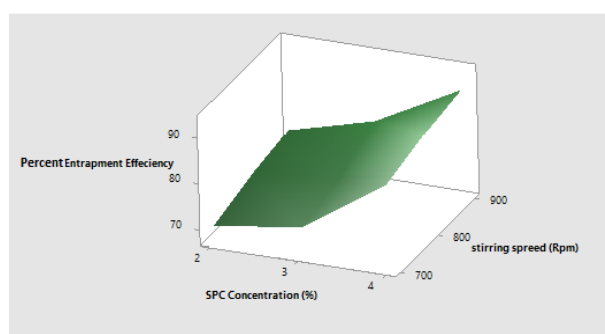

b

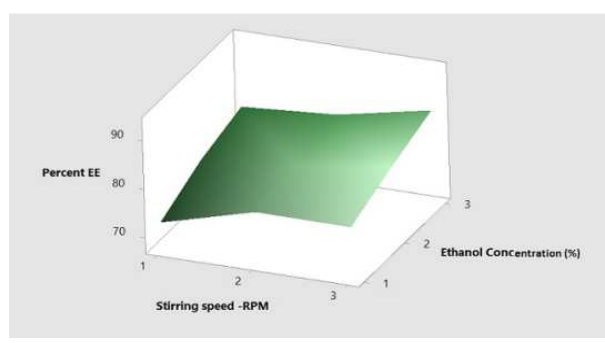

Fig. 3: Surface plot of percent entrapment efficiency, a Surface plot of \% EE VS ethanol concentration (\%), SPC concentration (\%), b Surface plot of \% EE VS ethanol concentration (\%), stirring speed-RPM, c Surface plot of \% EE VS stirring speedRPM, SPC concentration(\%) 
The final regression model equation obtained was expressed in equation 2 :

\section{$\% \mathrm{EE}=55.68+5.02 \mathrm{~A}+2.688 \mathrm{C}+1.61 \mathrm{~B}+1.128 \mathrm{~A} * \mathrm{~B}$}

Where it can be noticed that all the main factor have a positive influence on \% EE, among this lipid concentration had a more prominent effect. The influences of the main effects (factors) on responses (here, \% EE) were further elucidated by the surface plot as showed in fig. 3 a, b and c. Alcohol concentration and SPC concentration found to influence the stability of the formulation. The 2 $\% \mathrm{w} / \mathrm{v}$ of SPC concentration gave all stable formulation irrespective of the variations in ethanol concentration and stirring speed. At $4 \% \mathrm{w} / \mathrm{v}$ of SPC along with $35 \% \mathrm{v} / \mathrm{v}$ alcohol showed the problem of stability irrespective of stirring speed. Higher concentration of alcohol was found to impart stability to formulations having $4 \% \mathrm{w} / \mathrm{v}$ of SPC.

The optimum values of the variables are obtained by graphical and numerical based on the criterion of desirability using the prediction and optimization report as per fig. 4 by using Minitab.

The vesicle size and entrapment efficiency of the vesicular carrier are the parameters mostly influence the permeation of entrapped drug through the skin. For this reason, formulation F4E459 (4 \% SPC, $45 \%$ $\mathrm{v} / \mathrm{v}$ ethanol $900 \mathrm{RPM})$, which is characterized by optimum vesicle size $(5.5 \mu \mathrm{m})$ and high entrapment efficiency $(93.32 \%)$, was considered to be an optimal formulation and carried forward for further investigations.

Table 4: Results of ANOVA for the response parameter-\%EE

\begin{tabular}{|c|c|c|c|c|c|}
\hline Source & Sum of square & DF & Mean square & F-Value & P-Value \\
\hline Model & 1711.32 & 18 & 95.073 & 31.92 & 0.007 \\
\hline A & 1349.61 & 2 & 674.804 & 226.58 & 0.000 \\
\hline B & 190.52 & 2 & 95.260 & 31.99 & 0.000 \\
\hline $\mathrm{C}$ & 110.59 & 2 & 55.297 & 18.57 & 0.018 \\
\hline$A^{*} B$ & 14.41 & 4 & 3.602 & 1.21 & 0.048 \\
\hline$A^{*} \mathrm{C}$ & 30.56 & 4 & 7.640 & 2.57 & 0.120 \\
\hline $\mathrm{B}^{*} \mathrm{C}$ & 15.63 & 4 & 3.906 & 1.31 & 0.344 \\
\hline
\end{tabular}

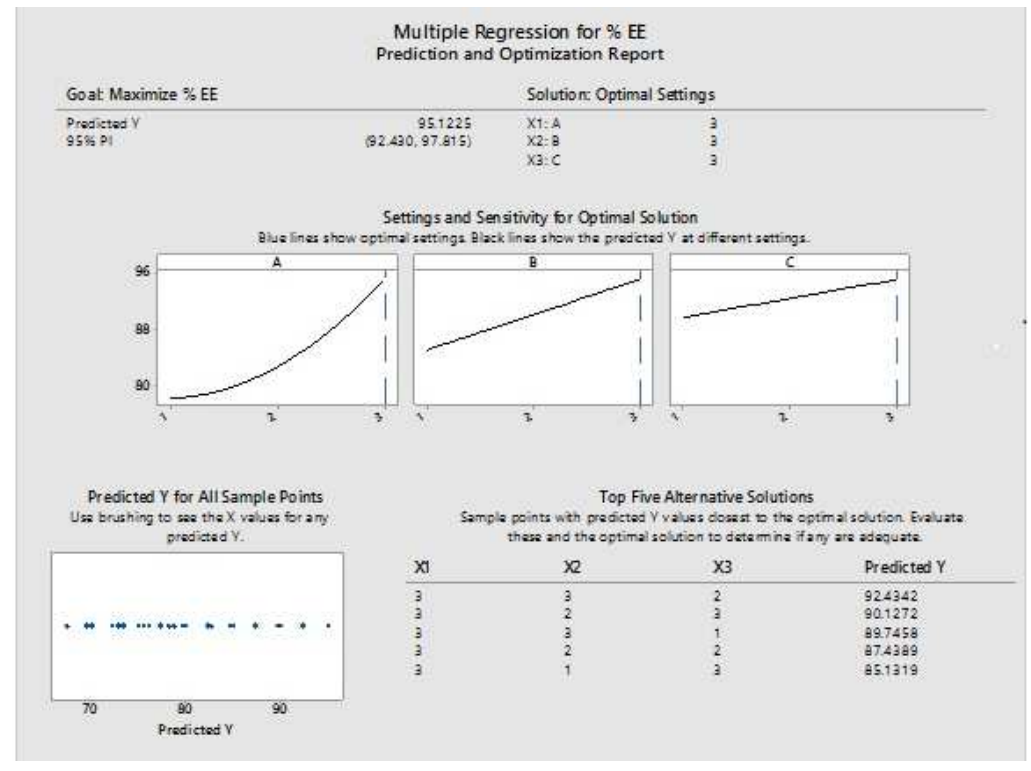

Fig. 4: Prediction and optimization report using minitab

\section{Evaluation of optimized formulation}

Ethosome system F4E459 was selected for further studies, as it offered the best compromise in characteristics: mean vesicle size, drug entrapment efficiency percentage and stability.

\section{SEM study}

It is seen from SEM photomicrograph fig. 5 that optimized ethosome vesicles are unilamellar, nano ranged with a smooth surface and showing some deviation in terms of spherical shape explaining the fluidizing effect of ethanol, a phenomenon observed earlier [16].

\section{Vesicle size distribution and surface charge}

The polydispersity index (PI) was determined as a measure of homogeneity of the formulation [11]. Dynamic Light Scattering (DLS) revealed small PI of the optimized formulation as $0.493 \pm 0.021$ (fig. 6) and the average vesicle diameter range of optimized ethosomal suspension was $226 \pm 7.42 \mathrm{~nm}$. A small value of PI $(<0.5)$ indicates a homogenous population of ethosome vesicles. The negative zeta potential values $(\leq-15 \mathrm{mV})$ was indicative of a good stability against vesicle aggregation and fusion [26]. The zeta potential of that ethosomal suspension was- $21.3 \mathrm{mV}$ which is sufficient to inhibit aggregation of ethosomes due to electric repulsion (fig. 7). This negative charge value of ethosomes is attributed to the presence of ethanol.

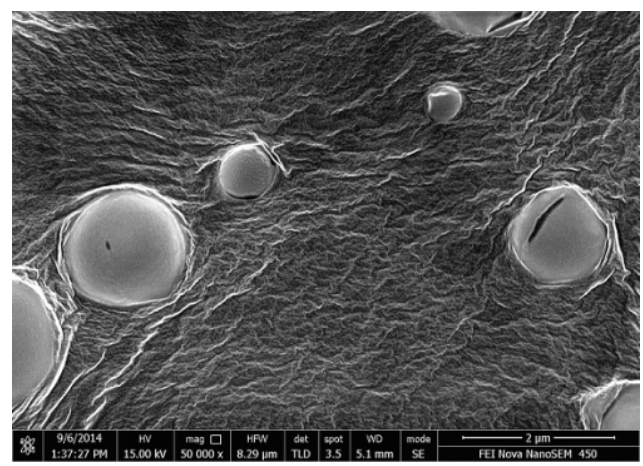

Fig. 5: SEM photograph 


$\begin{array}{rllll} & & \text { Size (d.um): } & \text { \% Inensity } & \text { Wicth idumk } \\ \text { Z.Average (d.smin: } 226.1 & \text { Peak 1: } & 355.3 & 75.5 & 237.4 \\ \text { Pdl: } 0.493 & \text { Peak 2: } & 75.10 & 17.9 & 17.50 \\ \text { Intercept: } 0.972 & \text { Peak 3: } & 4916 & 6.6 & 674.1\end{array}$

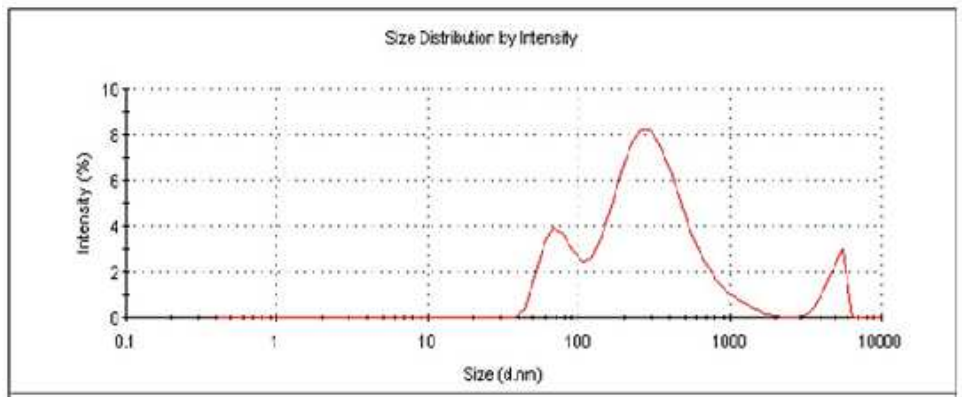

Fig. 6: Polydispersibility index of the optimized ethosome formulation
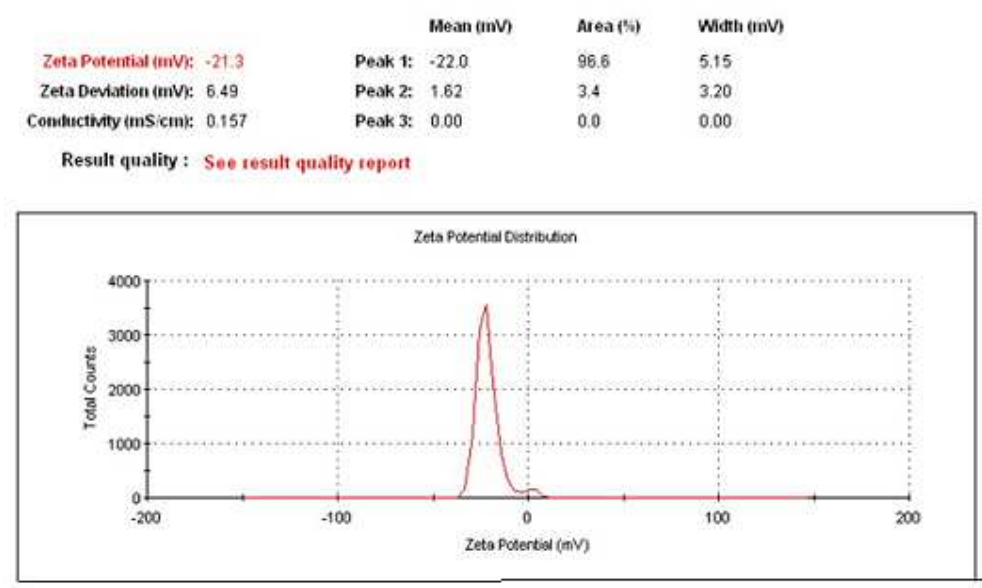

Fig. 7: Zeta potential of the optimized ethosome formulation

\section{Stability evaluation study}

Physical stability study of the optimized ethosome formulation was conducted at refrigeration temperature $\left[4 \pm 2{ }^{\circ} \mathrm{C}\right]$ and at room temperature $\left[25 \pm 2{ }^{\circ} \mathrm{C}\right]$ for a period of $3 \mathrm{mo}$. No significant changes in drug entrapment efficiency, as well as no signs of separation or change in colour, were observed for the formulation stored at refrigerated temperature. Low entrapment efficiency of ethosomes with marked separation and slight yellow discolouration was observed when stored at room temperature (table 5) as at room temperature ethosomes became unstable due to oxidation and become aggregated which led to leakage of the drug. The percent RBZ retained by ethosomal formulations after $90 \mathrm{~d}$ were $86.95 \pm 1.52 \%$ and $55.36 \pm 1.03 \%$ when stored at refrigerated and room temperature respectively. These results were in agreement with what has been previously recommended that ethosomal suspensions should be kept refrigerated to achieve the best stability [27].

Table 5: Stability study of RBZ ethosomes at different storage conditions

\begin{tabular}{llll}
\hline Time (mo) & Physical stability of dispersion & \%EE* \\
\hline & Storage at $4{ }^{\circ} \mathrm{C}$ & Storage at $25^{\circ} \mathrm{C}$ & Storage at $4{ }^{\circ} \mathrm{C}$ \\
0 & Uniform dispersion & Uniform dispersion & $92.26 \pm 1.23$ \\
1 & Uniform dispersion & Layer formation & $91.56 \pm 0.84$ \\
2 & Uniform dispersion & Layer formation & $82.26 \pm 1.23$ \\
3 & Uniform dispersion & Layer formation & $81.55 \pm 2.30$ \\
\hline
\end{tabular}

* SD standard deviation from mean, $\mathrm{n}=3$

\section{In vitro skin permeation studies}

The investigation of efficient prolong release ability of ethosomal formulation was done by Franz diffusion cell measurement using the abdominal portion of a rat. The percent cumulative amount of RBZ permeated across excised rat skin over $8 \mathrm{~h}$ periods was plotted against the function of time (fig. 8) and lag time was determined.
From the release profiles it was observed that after $3.5 \mathrm{~h}$, the maximum drug was permeated from the drug solution (99.1 $\pm 5.1 \%$ ), this explains the need for prolonging release formulation development. Optimized Ethosomal RBZ solution show a significant reduction in vitro drug release $(\mathrm{p}<0.001)$ in $3.5 \mathrm{~h}$ compared with the drug in solution. The release profile of RBZ from ethosome solution was biphasic. Initial rapid release up to $2 \mathrm{~h}$ which could probably be 
due to the portion of the drug that leaked out of ethosome and the unloaded drug followed by extended-release up to $8 \mathrm{~h}$ with around percent cumulative release of around $89 \%$ was observed. The very low viscosity often exhibited by ethosome is not suitable for topical use. The viscosity can be increased by adding thickening agents, which also change the appearance of the system, usually influencing drug release. As a vehicle for incorporation of ethosomes for skin delivery, the ethosome formulation was loaded in 1\% Carbopol 934[28]. Among the various hydrogel bases, Carbopol is used because of its high stability, compatibility and low toxicity [29]. In vitro release data of ethosomal gel revealed around $81 \%$ release of RBZ in $8 \mathrm{~h}$ in which around $26 \%$ release within $1 \mathrm{~h}$ which assumes to be sufficient as a loading dose. This bi-phasic pattern release is a characteristic feature of matrix diffusion kinetics. The ethosomal gel formulation showed controlled drug release due to the entrapment of drug in vesicles. Permeation study suggested that the gelling agent in the concentration used had little effect on drug release and that the rate-limiting step was the diffusion of the drug out of the ethosomes.

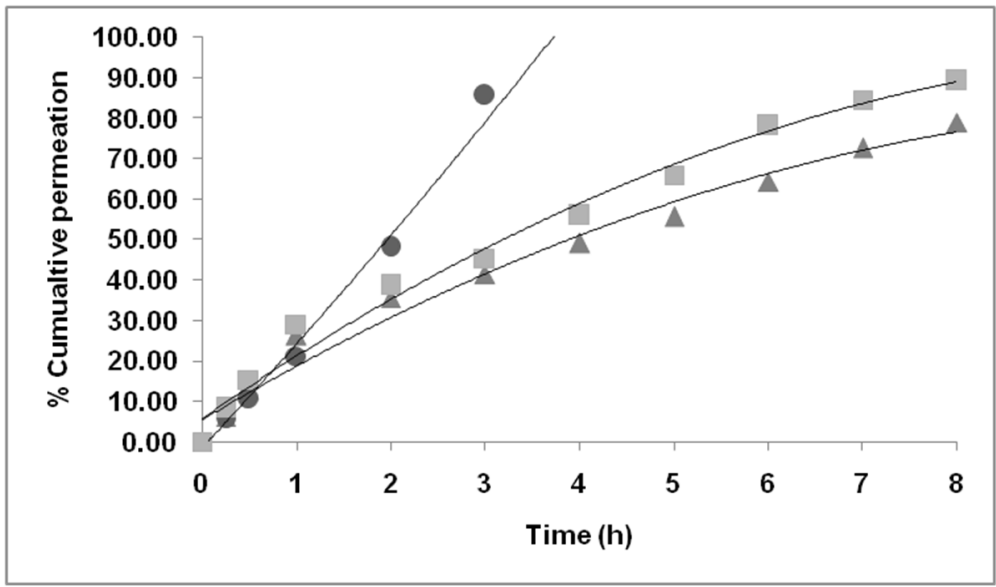

Fig. 8: Percent cumulative amount of in vitro RBZ permeated through rat skin vs. time profile of RBZ solution, $\bigcirc$ RBZ optimized ethosome solution $\square$ and gel $\triangle$, (mean $\pm S D, n=3)$

\section{Release kinetic studies}

The results of the curve fitting into for mathematical models of release kinetics after comparing the respective correlation coefficients indicate the in vitro RBZ permeation behaviour of the ethosomal solution and gel (table 6) were followed by the Higuchi model. The ' $n$ ' values for a solution and gel formulation were found to be 0.664 and 0.693 respectively which are more than 0.5 .

This indicates that the release approximates non-Fickian diffusion mechanism [30] and the gel was selected for next skin irritation studies.

Table 6: Kinetic models of formulation

\begin{tabular}{lllllc}
\hline Formulation & Zero-order & First order & Higuchi & \multicolumn{2}{l}{ Korsemeyer-Peppas } \\
\hline & R2 & R2 & R2 & N & R2 \\
Ethosome sol & 0.9746 & 0.8114 & 0.9854 & 0.664 & 0.9825 \\
Ethosome gel & 0.9493 & 0.7523 & 0.9892 & 0.693 & 0.9672 \\
\hline
\end{tabular}

Table 7: Skin irritation test

\begin{tabular}{|c|c|c|c|c|c|c|}
\hline \multirow[t]{2}{*}{ Groups } & \multicolumn{2}{|c|}{ Saline solution } & \multicolumn{2}{|c|}{ RBZ ethosomal gel } & \multicolumn{2}{|c|}{ Formalin solution } \\
\hline & \multicolumn{2}{|c|}{ Erythema score } & \multicolumn{2}{|c|}{ Erythema score } & \multicolumn{2}{|c|}{ Erythema score } \\
\hline & $24 \mathrm{~h}$ & $72 \mathrm{~h}$ & $24 \mathrm{~h}$ & $72 \mathrm{~h}$ & $24 \mathrm{~h}$ & $72 \mathrm{~h}$ \\
\hline Animal 1 & 0 & 0 & 0 & 0 & 2 & 2 \\
\hline Animal 2 & 0 & 0 & 0 & 1 & 3 & 3 \\
\hline Animal 3 & 0 & 0 & 0 & 0 & 3 & 2 \\
\hline Primary irritation index (PII) & \multicolumn{2}{|c|}{$\begin{array}{l}0 / 6=0 \\
\text { No irritation }\end{array}$} & \multicolumn{2}{|c|}{$\begin{array}{l}1 / 6=0 . \\
\text { Negligible irritation }\end{array}$} & \multicolumn{2}{|c|}{$\begin{array}{l}15 / 6=2.5 \\
\text { Moderate irritation }\end{array}$} \\
\hline
\end{tabular}

\section{Skin Irritancy test}

We conducted the skin irritancy studies of the ethosomal gel formulation. Measurement of erythema scores upon exposure of hairless rat skin to various formulations including saline solution $(0.9 \% \mathrm{w} / \mathrm{v} \mathrm{NaCl}$ solution, negative control), ethosomal gel formulation, and Formalin solution $(0.8 \% \mathrm{v} / \mathrm{v}$, positive control) as per table 7 revealed that saline and ethosomal gel showed no significant erythema, whereas remarkable skin erythema was observed with formalin solution, demonstrating that ethanol present in the ethosomal formulation is not able to act as a skin erythema inducing agent, even though present in high concentration. Irritation score (primary skin irritation index) of RBZ ethosomal gel was zero, which indicated its safety and acceptability for topical administration.

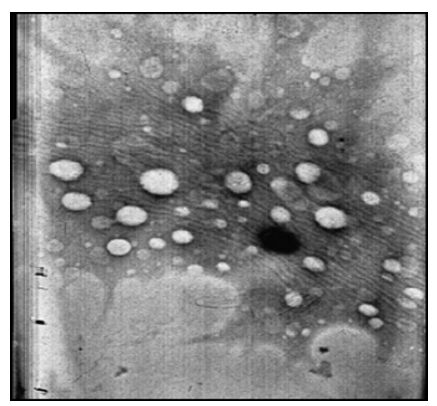

Fig. 9: The transmission electron microscopic image of optimized ethosomal gel formulation 


\section{Transmission electron microscopy}

It is seen from TEM photomicrograph that ethosomal vesicles are unilamellar in nature with nearly spherical shape (fig. 9) and also depicted the absence of aggregates. However, optimized ethosomal gel TEM photomicrograph also revealed that vesicles remain intact after dispersion into gel formulation.

\section{CONCLUSION}

The study revealed the development of ethosome carrier as suitable drug delivery system for RBZ considering the site-specific topical approach. $3^{3}$ full factorial designs were prepared and evaluated to study composition and processing factors influencing the formulation of ethosomes. The study demonstrated that all factors had a positive impact and interaction effect of lipid concentration and ethanol also found to be significant on \% EE. The ethosome formulation was optimized for maximum entrapment efficiency and RBZ ethosomal gel of optimized formulation was prepared and evaluated successfully for an in vitro permeation across the rat abdomen skin. It can be concluded that the ethosomal gel prepared with Carbopol 934P can be used without skin irritation and can release RBZ for $8 \mathrm{~h}$.

\section{ACKNOWLEDGEMENT}

The authors are grateful to M/s Cipla Ltd., India, for providing RBZ as a gift sample. The acknowledgement also goes to Dr. V. R. Undale (India) for her expert support for the animal study.

\section{AUTHORS CONTRIBUTIONS}

All the authors have contributed equally

\section{CONFLICTS OF INTERESTS}

Declare none

\section{REFERENCES}

1. Cumberbatch MJ, Hill RG, Hargreaves RJ. Rizatriptan has central antinociceptive effects against durally evoked responses. Eur J Pharmacol 1997;328:37-40.

2. Lee Y, Conroy JA, Stepanavage ME, Mendel CM, Somers G, Mcloughlin DA, et al. Pharmacokinetics and tolerability of oral rizatriptan in healthy male and female volunteers. Br J Clin Pharmacol 1999;47:373-8.

3. Ramadan NM, Buchanan TM. New and future migraine therapy. Pharmacol Ther 2006;112:199-212.

4. Fontebasso M. Current treatment options in the management of a migraine. Prescriber 2008;19:42-58.

5. Lahoti SR, Taur NG, Khan AR, Puranik PK. Enhanced Iontophoretic permeation of rizatriptan benzoate from the thermo-reversible gel based system: effect of penetration enhancers and pulsed current. Indian J Pharm Educ Res 2012;46:105-11.

6. Aung-din R. European patent 1435945 b1. 2008;1:1-17.

7. Sharma A, Tiwary AK. Elastic liposomal formulation for sustained delivery of antimigraine drug: in vitro characterization and biological evaluation. Drug Dev Ind Pharm 2008;34:1100-10.

8. Aung-din R. United States Patent; 2012. p. 2.

9. Femenía Font A, Balaguer Fernández C, Merino V, Lopez Castellano A. Iontophoretic transdermal delivery of sumatriptan: effect of current density and ionic strength. J Pharm Sci 2005;94:2183-6.

10. Aung Din R. United States Patent; 2012. p. 2.

11. Dubey V, Mishra D, Jain NK. Melatonin loaded ethanolic liposomes: Physicochemical characterization and enhanced transdermal delivery. Eur J Pharm Biopharm 2007;67:398-405.
12. Dubey V, Mishra D, Dutta T, Nahar M, Saraf DK, Jain NK. Dermal and transdermal delivery of an anti-psoriatic agent via ethanolic liposomes. J Controlled Release 2007;123:148-54.

13. Dubey V, Mishra D, Nahar M, Jain V, Jain NK. Enhanced transdermal delivery of an anti-HIV agent via ethanolic liposomes. Nanomed Nanotechnol Biol Med 2010;6:590-6.

14. Menon S, Verma D, Khuroo T, Talegaonkar S, Iqbal Z. Extraction of a water soluble bioactive hypoxoside and its development into an ethosomal system for deep dermal delivery. Int J Pharm Pharm Sci 2015;7:211-5.

15. Nair R, Kumar KSA, Vishnu K, Badivaddin T, Sevukarajan M. Preparation and characterization of rizatriptan loaded solid lipid nanoparticles. J Biomed Sci Res 2011;3:392-6.

16. Touitou E, Dayan N, Bergelson L, Godin B, Eliaz M. Ethosomesnovel vesicular carriers for enhanced delivery: Characterization and skin penetration properties. J Controlled Release 2000;65:403-18.

17. Touitou E, Godin B, Dayan N, Weiss C, Piliponsky A, LeviSchaffer F. Intracellular delivery mediated by an ethosomal carrier. Biomaterials 2001;22:3053-9.

18. Esposito E, Menegatti E, Cortesi R. Ethosomes and liposomes as topical vehicles for azelaic acid: a preformulation study. J Cosmet Sci 2004;55:253-64.

19. Rao Y, Zheng F, Zhang X, Gao J, Liang W. In vitro percutaneous permeation and skin accumulation of finasteride using vesicular ethosomal carriers. AAPS PharmSciTech 2008;9:860-5.

20. Li G, Fan Y, Fan C, Li X, Wang X, Li M, et al. Tacrolimus-loaded ethosomes: Physicochemical characterization and in vivo evaluation. Eur J Pharm Biopharm 2012;82:49-57.

21. Rao Y, Zheng F, Zhang X, Gao J, Liang W. In vitro percutaneous permeation and skin accumulation of finasteride using vesicular ethosomal carriers. AAPS PharmSciTech 2008;9:860-5.

22. Azeem A, Ahmad FJ, Khan ZI, Talegaonkar S, Azeem A, Ahmad FJ, et al. Nonionic surfactant vesicles as a carrier for transdermal delivery of frusemide. J Dispers Sci Technol 2008;29:37-41.

23. Pawar AP, Gholap AP, Kuchekar AB, Bothiraja C, Mali AJ. Formulation and evaluation of optimized oxybenzone microsponge gel for topical delivery. J Drug Delivery 2015:1-9. http://dx.doi.org/10.1155/2015/261068

24. Mohammed MI, Makky AMA, Abdellatif MM. Formulation and characterization of ethosomes bearing vancomycin hydrochloride for transdermal delivery. Int J Pharm Pharm Sci 2014;6:190-4.

25. Dayan N, Touitou E. Carriers for skin delivery of trihexyphenidyl $\mathrm{HCl}$-ethosomes vs liposomes. Biomaterials 2000;21:1879-85.

26. Manconi M, Sinico C, Caddeo C, Vila AO, Valenti D, Fadda AM. Penetration enhancer containing vesicles as carriers for dermal delivery of tretinoin. Int J Pharm 2011;412:37-46.

27. Li G, Fan C, Li X, Fan Y, Wang X, Li M, et al. Preparation and in vitro evaluation of tacrolimus-loaded ethosomes. Sci World J 2012:1-6. http://dx.doi.org/10.1100/2012/874053

28. Verma P, Pathak K. Nanosized ethanolic vesicles loaded with econazole nitrate for the treatment of deep fungal infections through topical gel formulation. Nanomed Nanotechnol Biol Med 2012;8:489-96.

29. Nimisha, Srivastava K, Singh AK. Formulation and evaluation of seabuckthorn leaf extract loaded ethosomal gel. Asian J Pharm Clin Res 2015;8:309-12.

30. Dash S, Murthy PN, Nath L, Chowdhury P. Kinetic modelling on drug release from controlled drug delivery systems. Acta Pol Pharm 2010;67:217-23. 